\title{
Early Dylipidaemia in Preganacy and the Risk of Pre-Eclampsia: A Longitudinal Study of African Gravid Women
}

\author{
Ganiyu O. Adeosun, Mabel A. Charles Davies, Omobola A. Ogundahunsi, Jaye Ogunlewe, \\ Ibrahim S. Bello, Tonia Chidinma Onyeneke
}

\begin{abstract}
Background: Preeclampsia and eclampsia, are the frequent and global obstetrics and gynaecology emergencies in the care of gravid women particularly in African women. Research efforts to identify predictors for recognizing pregnancy that will come down with preeclampsia is still a continuum, yet no single or combination of indices have absolute predictive potential for diagnosing preeclampsia.

OBJECTIVE: To evaluate the predictive potentials of sequential alterations of plasma lipids and to determine the gestation age at which dyslipidemia became pathologic to suspect the onset of preeclampsia in gravid African women.
\end{abstract}

Study design: This is a longitudinal study conducted in two phases at the antenatal clinics of a Tertiary hospital. The first Phase was semi-longitudinal and cross-sectional which involved 79 pre-eclamptic and 80 normotensive pregnancy respectively recruited at $3^{\text {rd }}$ trimester but followed up to 3days post-partum. The second phase was a full longitudinal study comprising 10 preeclamptic and 20 normotensive healthy pregnant women recruited from the first trimester of pregnancy but were observed up to six weeks post-delivery.

Methods: Plasma samples from $\mathrm{K}_{2}{ }^{+}$EDTA anti-coagulated blood obtained from the preeclamptic and normotensive gravid women at each trimester and postpartum were assayed for lipid profile. which included Triglyceride, Total-Cholesterol, HDLCholesterol by an enzymatic method. VLDL-Cholesterol and LDL-Cholesterol values were calculated.

Result: We recorded a sequential and steady increase in all the lipid fractions in both study and controls subjects with the progression in gestation age. Dyslipidaemia was significant $(p<0.001)$ in the preeclamptics at $10.9^{\text {th }}$ week of gestation relative to the controls. Triglyceride alterations became significant $(\mathbf{p}<0.001)$ and pathologic to speculate the development of preeclampsia at $10.9^{\text {th }}$ week of gestation (ODS=29.952, $\mathrm{CI}=1.046-857.998 @ \mathrm{P}<0.04$. The lipids regressed significantly to almost pre-pregnancy values at 6 weeks postpartum.

Ganiyu O. Adeosun, Department of Medical Laboratory Science, University of Medical Sciences, Ondo City, Ondo State.,Nigeria

Mabel A. Charles Davies, Department of Chemical Pathology \& Immunology, University College Hospital Ibadan, Nigeria.

Omobola A. Ogundahunsi, .Department of Chemical Pathology \& Immunology, Olabisi Onabanjo University Ago-Iwoye, Nigeria

Jaye Ogunlewe, Department of Chemical Pathology \& Immunology, Olabisi Onabanjo University Ago-Iwoye, Nigeria

Ibrahim S. Bello, .Department of Family Medicine Obafemi Awolowo University Teaching Hospital Ile-Ife, Nigeria,

Tonia Chidinma Onyeneke, Department of Medical Laboratory Science, Andrews University, Michigan, MI 49104, USA

Corresponding Author: Ganiyu Oyebola. Adeosun, Department of Medical Laboratory Science, University of Medical Sciences, Ondo City, Ondo State.
Conclusion: Physiologic alterations of plasma lipids in early pregnancy can become pathologic to precipitate preeclampsia. Dyslipidaemia and alteration of cardiac risk ratio does not put gravid women at the risk of atherosclerosis.

Index Terms - Cardiac risk ratio, Dyslipidaemia Lipid, Preeclampsia, Predictors.

\section{INTRODUCTION}

Pregnancy and child delivery are means of procreation and remain a source of joy to humans but the associated joy might be truncated by the unpredictable extreme negative outcomes of pregnancy such as maternal - neonatal mortality and morbidity $_{[1]}$. Studies have shown that hemorrhage, sepsis, obstructed labour, and hypertensive disorders of pregnancy have been implicated by various authors as risk factors of maternal - perinatal mortality and morbidity among gravid women [2] with pregnancy-induced hypertension; preeclampsia and eclampsia being the frequent aetiology of maternal and perinatal mortality globally [3]

Preeclampsia is the presence of new-onset hypertension $(\geq$ $140 \mathrm{mmHg} / 90 \mathrm{mmHg}$ ) experienced during pregnancy in a woman previously normotensive [2]. The disorder is a heterogeneous syndrome characterized by a blood pressure greater than or equal to $140 / 90 \mathrm{mmHg}$ (Mild preeclampsia) or greater than or equal $160 / 110$ (severe preeclampsia) $\mathrm{mmHg}$ measured on two occasions, at least six hours apart with proteinuria of greater than or equal to $300 \mathrm{mg} / 24$ hours or $2+$ dipstick post 20 weeks of gestation in previously normotensive women. When intervention is delayed, it progressed to severe form indicated by blood pressures of $\geq$ $160 \mathrm{mmHg} / 110 \mathrm{mmHg}$ leading to end-organ dysfunction such as eclampsia or acute kidney or heart failure necessitating immediate fetal delivery which can precipitate immediate Caesarean section. [4] Eclampsia is defined as the presence of seizure and disrupted level of consciousness never induced by epilepsy or associated convulsive disorders but associated with symptoms of severe preeclampsia. This pregnancy-specific disease is an obstetric emergency occurring in about 2-8\% of pregnancies [5] [6] and accounted for more than 60,000 maternal and 500,000 fetal deaths per year worldwide .[7]

In Nigeria, 5.6- $7.6 \%$ [8 ]- $[.9$ ]and40\% [10] of pregnancies in the southern and Northern Nigeria respectively, are complicated by preeclampsia.[10] A recent report shows that the foremost cause of maternal and 
perinatal mortality reported in Nigeria over the last decade are fatalities from preeclampsia and eclampsia with eclampsia being most responsible. [11]

In spite of this awareness, pre-eclampsia still possesses high danger to the gravid women because its onset is unpredictable and the etiology remains inconclusive and presumptive despite extensive research [12] but conceptualize to have multiple pathogeneses.[13] The efforts to unravel the mystery behind the pathology of preeclampsia and search for a reliable screening and confirmatory indices to identify women who may develop this disease must be a continuum. [12] Physiological dyslipadaemina in pregnancy which is a component of metabolic syndrome, has been perceived to be an important predisposing feature of pre-eclampsia [14]. Metabolic disorders are a group of abnormal health status such as hypertension, raised cholesterol, hypertriglyceridaemia, and excess body fat around the waist, which double the risk of cardiovascular disorders. Pregnant women with pre-eclampsia are more likely to exhibit relative hypertriglyceridaemia, hypercholesteroalaemia, and gestational diabetes.

Our previous study on unravelling the aetiology of pre-eclampsia implicated significant lipid and hormone alterations as the probable predisposing indices of pre-eclampsia [15] but the study could not determine the mechanism between physiological dyslipidaemia and the development of preeclampsia in gravid women; this portends an obvious research gap. This current effort is the continuation of our previous work [15] which was focused on filling this research gap through a longitudinal evaluation of pregnancy from the first trimester to the six post-delivery periods.

We believe this attempt may serve as a timely intervention in identifying pregnancy that will end up with preeclampsia and also identify the correlation between physiological dyslipidaemia and the development of preeclampsia in gravid women. The findings of this research might also determine the age of the pregnancy at which lipid alterations become pathologic and significant to speculate the development of preeclampsia. Research reports of lipids in preeclamptic on longitudinal study of gravid women usually come from the with Caucasian subjects, whereas there is a paucity of similar information on gravid African women.

\section{MATERIALS AND METHODS}

\section{Study design}

The research is a two- phase structure, longitudinally administered in two phases; half and full longitudinal phases. The case and control subjects were monitored at the early pre-delivery pregnancy stage to six weeks post foetal delivery through antenatal and post-natal clinic appointments.

\section{Study setting}

The research was conducted in two phases;

\section{Phase one}

Three hundred and fifty gravid women were involved in phase one of this study; out of this figure seventy-nine were preeclamptic and met the eligibility criteria and as well gave consent to participate in the study. Eighty participants had consistent normotensive blood pressure throughout the study period and gave their consent, thus serve as the control. The cases and control groups were monitored from the point of selection (35-38 weeks) up to 3 days postpartum. The outliner; one hundred and ninety-one subjects were excluded either due to the decline of consent occasioned by the doubt of completing the antenatal care at the research center, or some having other pregnancy complications like diabetes, renal disease, hypertension, and anemia. The data of these outliners were not analyzed.

Phase two: This was the follow up of phase one of the study design aimed at detecting the onset of the abnormalities observed in phase one of this research. One hundred healthy normotensive pregnant women with mean gestation age between 8-13 weeks without proteinuria were selected from the antenatal clinics of the Tertiary Teaching Hospital after obtaining their informed consent. They were screened for early pregnancy disorders using the established report of the National High Blood Pressure Education Program Working Group on high blood pressure in pregnancy [21].These subjects were monitored from the mean gestation age of recruitment; $10.9 \pm 0$ to 6 weeks post-partum through their antenatal and postnatal clinic day appointments. While the follow up was ongoing, thirty (30) participants met the study criteria, and ten (10) out of these, thirty (30) participants developed pre-eclampsia and were grouped as cases of interest. Twenty remained normotensives without developing proteinuria throughout the research period, they served as controls. The remaining seventy (70) gravid subjects were excluded due to their inability to meet the research criteria. Blood specimen obtained at each defined point of contact during the research period which was analyzed for the lipid profile fractions using enzyme-based standard colourimetric methods [16]

. The cases and control subjects were selected from the antenatal clinics and wards of a Tertiary Teaching Hospital in Ile-Ife- Southwest Nigeria.

Blood was collected into a $\mathrm{K}_{2}^{+}$EDTA anti- coagulant bottle at each semester of the pregnancy during the antenatal and postnatal clinic appointments. Plasma harvested from the anti-coagulated blood was preserved at -80 degrees Celsius for the estimation of total cholesterol, triglyceride, and HDL using standard enzyme-based colourimetric methods described by Umoh et al., [16 ] while LDL and VLDL were calculated.

\section{Analytical methods}

Triglyceride (TG) was assayed by enzymatic methods described by Cole et al [17] using Randox Diagnostic-Crumlin, United Kingdom while Total cholesterol was estimated using the enzymatic method as described by Trinde [18] with the reagent purchased from Randox Diagnostics, Crumlin, United Kingdom. Plasma HDL-C assay was carried out using the enzymatic method as described by Frieldwald et al.[19] with Randox Diagnostics reagents from Crumlin, United Kingdom. The estimation of LDL and VLDL was accomplished by the application of the Friedewald formula.[19]-[20]

\section{Baseline values}


Reference values of demographic anthropometric, clinical, and biochemical indices for statistical analyses were taken at a mean gestation age of $10.9 \pm 0.3$ weeks for the phase two (2) section and at the mean gestation age of $35.7 \pm 0.0 .4$ weeks for the phase one (1). The biophysical and clinical data were obtained from the patients' case notes while biochemical data were results from the assay of the lipid fractions

\section{Diagnosis of preeclampsia and eclampsia and Definition terms}

Preeclampsia is a pregnancy-specific abnormality characterized by new-onset hypertension (blood pressure of $>140 / 90)$ and proteinuria (2+ protein dipstick testing)), occurring usually after 20 weeks' gestation [21]

Severe preeclampsia was defined as new hypertension with a blood pressure of $160 \mathrm{mmHg}$ systolic or diastolic blood pressure of $110 \mathrm{mmHg}$, or greater, arising after 20 weeks of gestation in a woman who was normotensive before 20 weeks gestation, associated with proteinuria. Proteinuria was defined as a finding of $3+$ or more protein on urine dipstick.

Eclampsia was defined as the occurrence of seizure and/or altered level of consciousness not caused by epilepsy or other convulsive disorders, with signs of severe preeclampsia diagnosed according to the criteria described by the National high blood pressure education program working group on high blood pressure in pregnancy. [21]

\section{Ethical consideration.}

Recruitment of participants for the 2- year study started after the study design was approved by the local Ethics and Research Committee of the tertiary hospital (Obafemi Awolowo University Teaching Hospital, Ile-Ife) in Southwest Nigeria where the study was conducted.

\section{Calculation of Sample size.}

The sample size was calculated using the formula described by (Rendon-Macias, et al., .[22]

Sample size $=\mathrm{Pq}(\mathrm{z}) 2$ /e.

Where: $\mathrm{Z}=$ Standard deviation, $\mathrm{e}=$ Margin of error, $\mathrm{p}=$ prevalence of preeclampsia in the study area.

Eligibility criteria: This included normotensive and non-proteinuric antenatal cases registered before 13 weeks of gestation and voluntarily accepted to be involved and ready to complete the study.

Exclusion criteria: This comprises hypertensive and proteinuric pregnancy before or at 13 weeks of gestation and recruited subjects who declined consent during the study period.

\section{Statistical analysis}

The data from the study were analyzed using SPSS version 21.0. Consistent variables were presented as the mean and standard error of the mean. While categorical variables were presented as percentages. Differences between groups were compared using a two-tail independent t-test of significance at a 95\% confidence limit, $p<0.05$ was considered significant for the variables. Multiple Logistic regression package to predict a dichotomous outcome from one or more predictor variables and the significance of each predictor in the package was tested while all other predictors were held constant. The effect of size for the individual predictor was expressed as an Odds Ratio (OR). and the $P$-value (for the OR) was less than 0.05 , and the OR was more than 1.1 or less than 0.90 in the univariate analysis.

\section{RESUlts}

\section{Phase one:}

Table 1 shows the demographic characteristics of preeclamptic and normotensive pregnancies. The incidence of pre-eclampsia was higher $(p<0.05)$ within the age bracket of 25-34. Gestational age at delivery among the preeclamptics was significantly lower compared with the controls $(p<$ 0.05). Delivery by Caesarian Section in preeclampsia was 57 $(81.4 \%)$ and $17(24.3 \%)$ progressed to eclampsia. Two maternal $2(2.9 \%)$ and nine neonatal deaths $9(12.9 \%)$ b were recorded among the preeclamptics. Baseline and postpartum values BMI and blood pressure of cases and controls are presented (Table 2). Systolic and diastolic blood pressures were higher $(p<0.001)$ among the preeclamptics at pre and postpartum when compared with normotensive pregnancy (Table 2). The mean baseline values of the lipid fractions and coronary artery risk ratio before and after delivery were compared and presented in table 3 . Predelivery Triglyceride, Total cholesterol, High, Low and very density lipoprotein -cholesterol baseline concentrations were significantly elevated in the preeclamptics when compared with the controls $(\mathrm{p}<0.001)$, while the coronary artery disease (CAD)risk ratio between the two groups were statistically comparable $(p>0.05)$. The differences in the mean values of Triglyceride, Total Cholesterol, and very density lipoprotein -cholesterol only after foetus delivery between case and control was not significant $(\mathrm{p}>0.05)$. However, LDL-C and CAD risk ratio was significantly lower $(\mathrm{p}<0.001)$ and HDL-C significantly higher $(\mathrm{p}<0.001$ in cases than the controls postpartum (Table 3 )

Phase two: The comparative analysis of anthropometric and clinical indices in both study and control subjects from the first trimester to six weeks postpartum is presented in Table 5. The values of the anthropometric indices between study and control groups throughout gestation and post-partum are statistically comparable ( $p>0.05)$. The mean Systolic and Diastolic blood pressure values in the preeclampsia patients were significantly elevated $(p<0.001)$ when compared with the normotensive controls except in the $1^{\text {st }}$ trimester. The sequence of the alterations in the mean values of micro-albumin in preeclamptic patients throughout the study periods is similar to that of the blood pressures $(\mathrm{p}<0.001)$.Table 6 and figures 1-4 show the sequential and significant alterations in the mean values of the lipids, lipoprotein cholesterol fraction and coronary artery disease risk ratio indices from $1^{\text {st }}$ trimester to $3^{\text {rd }}$ trimester followed by a significant progressive decline from 3days to 6weeks postpartum among the preeclamptic pregnancy $(\mathrm{p}<0.001)$. The result of the logistic regression analysis to validate the predictive potentials of the lipids and the lipoprotein cholesterol fractions is presented in Table 7. Triglyceride only with the following statistics $(\mathrm{OR}=29.952$, $\mathrm{CI}=1.046-857.998, \quad \mathrm{p}<\quad 0.004), \quad(\mathrm{OR}=8.2584, \quad \mathrm{CI}=$ 7.169-9.5138, $\quad \mathrm{p}<0.018), \quad \mathrm{OR}=3.9991, \quad \mathrm{CI}=6.851-2.3525$, 
$\mathrm{p}<0.0110$ at $1^{\text {st }}, 2^{\text {nd }}$, and $3^{\text {rd }}$ trimester respectively have significant predictive potentials for pre-eclampsia at first, $2^{\text {nd }}$ and $3^{\text {rd }}$ trimester.

\section{DISCUSSION}

The unending adverse health impacts of preeclampsia on the gravid mother, foetus, and the economy of a nation have made this pregnancy-specific disease a continuous subject of discourse among researches worldwide. That preeclampsia and eclampsia contribute significantly to high maternal and foetal- mortality and morbidity in developed and developing countries are incontrovertible yet the aetiopathogenesis is still elusive.[23] As much as we know till moment, search for a single or combination of predictive factors of preeclampsia is still on-going [23]. Alteration of lipid metabolism in pregnancy has been associated with the development of preeclampsia, however, there is yet to be consensus on this theory due to varying dyslipidaemic pattern reported in the literature,[15],[24- 28]

In phase one of this present study, we observed significant late 3rd-trimester maternal elevation of all the lipid fractions among the study group who eventually developed preeclampsia. The preeclamptics had elevated triglyceride, total cholesterol, HDL-Cholesterol, and LDL-cholesterol $(\mathrm{P}<$ 0.001 ) as compared with pregnant women who had sustained normal lipid levels throughout the study or pregnancy period.

The hyper lipidaemia observed in the 3rd-trimester pregnancy suggests that dyslipidaemia could make gravid women vulnerable to the development of preeclampsia. We observed late (3rd-trimester) maternal dyslipidaemia in pregnancy in phase one of this study and might be an indication that alterations of lipids could be a probable predictor of preeclampsia and this has been reported [15], which aligns with previous studies that associated elevated plasma lipid fractions in late pregnancy with the development of preeclampsia [25-28]. Those studies were inconclusive or limiting because the precise gestational age when the dyslipidaemia became pathologically significant to suspect the development pre-eclampsia could not be ascertained in their reports, hence the justification for the longitudinal study in phase two of this current research.

In the longitudinal study, we observed early first-trimester differential and progressive lipid alterations in both study and control subjects throughout pregnancy (Table 6, figures1-4) however the lipid alterations were much pronounced in the study group. Early significant hyper lipidaemia $(\mathrm{p}<0.001)$ commenced at the10.9th week of gestation among the preeclamptics in the longitudinal study as demonstrated by the significant differential progressive alterations of all the lipid fractions from $1^{\text {st }}$ to $3^{\text {rd }}$ trimester and up to 6weeks post-partum ( $\mathrm{p}<0.001$; Table 6 , figures $1-4)$. The upsurge of triglyceride and cholesterol, HDL-C, and LDL-C among the preeclamptics between early second trimester and late3rd trimester (23.4-35.6 weeks), which are the optimum peak period for the onset of preeclampsia for the vulnerable pregnancy might be a reason why the study group developed preeclampsia. The dyslipidaemic pattern, particularly significant hypertriglyceridemia and hypercholesterolemia observed at first (11.3weeks), second (23.5weeks) and third trimester $(35.4$ weeks $) \quad(\mathrm{p}<0.001) \quad$ that precipitated preeclampsia in this study compares well with earlier reports of elevated lipids in pregnancy before 20 weeks gestation in women with future pre-eclampsia ${ }^{29-33}$. The observation of this current study is an improvement over these earlier reports [29-33], being a longitudinal study and that the observed significant elevations of triglyceride and cholesterol $(\mathrm{p}<0.001)$ became detectable as early as 10.9 th week of gestation among the preeclamptics.

Physiological alterations of lipids in pregnancy are necessary to ensure a sustained supply of nutrients to the growing foetus, as well as for the provision of lipid requirements of steroidogenesis for maternal and foetal well-being in pregnancy. It may, therefore, be inferred that the alterations of lipid metabolism in pregnancy are not pathogenic and hence cannot be associated with any adverse pregnancy outcome like preeclampsia, eclampsia, and hypertension; what then are the reasons for the vulnerability of physiological dyslipideamic gravid women to preeclampsia.?

Our findings show that, both the control and study group belong to the same socio-economic background and none of the demographic and anthropometric indices tested correlated with the lipid and its lipoprotein cholesterol fractions. Similarly, diastolic blood pressure only in the third trimester is the only clinical indices that have a significant direct correlation $(p<0.001)$ with the triglyceride. What then is the mechanism responsible for making dyslipidaemia particularly hypertriglyceridemia and hypercholesterolemia predisposes pregnancy to pre-eclampsia if the relationship between lipid and pregnancy is only casual as observed in control subjects of this present work?

Physiological alteration of lipid metabolism in preeclamptic pregnancy might have been exaggerated to become pathologic to precipitate preeclampsia before foetal delivery because the control remained normolipidemic devoid of any pregnancy complications till foetus delivery and postpartum .This observation aligns with the reports of 34-37 that attributed a possible defect in the mechanism for adjusting physiologic hyper lipidaemia in pregnancy which might be a consequence of endothelial cell damage and a precipitating factor of pre-eclampsia [38]-[39]. In this present study, the control subjects had physiological hypertriglyceridemia (tables3 and 6), a major index of metabolic syndrome which significantly predisposes to the development of pre-eclampsia [40], despite this, the controls were protected from coming down with preeclampsia before and after foetal delivery.

Our observation of differentially regulated plasma lipid alterations particularly, hyperlipoproteinaemia (LDL-C), hypertriglyceridaemia and hypercholesterolaemia with hypertriglyceridaemia reported being mostly differentially disrupted have been observed in some studies to be elevated two to three folds in the disruption of lipid and lipoprotein profile in normal pregnancy which can further be complicated in preeclampsia[ 41]-[43]. Besides, the elevated concentration of very-low-density lipoprotein(VLDL) observed in this study (table 6, figure 6 ) has been linked with 
hypertriglyceridemia which influences the entry of VLDL that transports endogenous triglyceride into circulation and thus gets deposited on the maternal uterine and renal vascular endothelium and thus causing injury to it.

The above theories may justify the mechanism behind the vulnerability of physiologic hyperlipideamia in pregnancy to preeclampsia. The observed exaggerated physiologic hypertriglyceridaemia might be due to the overproduction of estrogen in pregnancy associated with oestrogen elevation.[44] The exaggerated physiologic alterations of the lipids particularly triglyceride and cholesterol impressed us to speculate that dyslipidaemia has a link with the development of preeclampsia and might, therefore serve as an efficient biomarker for predicting and diagnosing preeclampsia (Tables $6 \& 7$. figures 1-4). We then proceeded to evaluate the strength and potentials of the differential alterations of the lipids in predicting future development pre-eclampsia with the multiple logistic regression statistics (table7). The result revealed that triglyceride only with the following statistics $\mathrm{OR}=29.952, \mathrm{CI}=1.046-857.998, \mathrm{p}<0.004),(\mathrm{OR}=8.2584, \mathrm{CI}=$ 7.169-9.5138, $\mathrm{p}<0.018), \quad \mathrm{OR}=3.9991, \quad \mathrm{CI}=6.851-2.3525$, $\mathrm{p}<0.0110$ at $1^{\text {st }}, 2^{\text {nd }}$, and $3^{\text {rd }}$ trimester respectively have significant predictive potentials for pre-eclampsia at $1 \mathrm{st}, 2^{\text {nd }}$ and $3^{\text {rd }}$ trimester with decreasing strength (OR) but with increasing probability ( $\mathrm{p}$-value) as the pregnancy advances in gestational age. The predictive potentials of cholesterol and other lipid fractions were insignificant and thus may not serve as biomarkers of preeclampsia. The result of the multiple regression analysis of the present study substantiates the correlation of

dyslipidaemia particularly hypertriglyceridaemia as a biomarker of future development of pre-eclampsia as previously reported in some previous studies elevated triglyceride as a high-risk factor of preeclampsia, [30],[40-43] and also portends a possible risk factor for cardiovascular complications. This influenced us to proceeded to evaluate the risk of cardiovascular disease among subjects (CVD) by investigating the vulnerability of the preeclamptics to the development of coronary artery disease CAD) by calculating cardiac risk ratio (TC/HDL)) as a predictor of atherosclerosis in pregnancy (tables 3,4,6 figures 6). Our observation shows a significant elevation of the cardiac risk ratio among the study group but with a sequential decrease in cardiac risk indices in both study and controls with advancing gestation age and postpartum. This signifies that preeclampsia and normotensive pregnancy are possibly protected from the risk of atherosclerosis with the study group been more protected (table 6, figure 6) and thus substantiating that pregnancy is immuned from the risk of atherosclerosis. This observation is consistent with previous reports that documented a continuous decrease in TC/HDL with advancing gestational age in pregnancy [24],[45] The nnormotensive and preeclamptic pregnancies in this our study subjects had dyslipidaemia and altered TC/HDL ratio but are immuned from the risk of atherosclerosis. This is at variance with the observations among the Caucasians where dyslipidaemia and altered TC/HDL ratio in pregnancy are risk factors of atherosclerosis [33],[46].

\section{CONCLUSION.}

We conclude that sequential alterations of lipids and its lipoprotein cholesterol fractions portends high-risk factor for the onset of preeclampsia in pregnancy. Significant dyslipidaemia particularly hypertriglyceridaemia at the early gestation age of 10.9 weeks makes pregnancy vulnerable to developing preeclampsia with increasing predictive potentials with advancing gestational age. Dyslipidaemia and altered cardiac risk factor (TC/HDL) does not predispose pregnancy to artherocsclosis in preeclamptic and normotensive pregnancies. 
VI. RESULTS

Results. Phase 1

Table 1: Demographic Characteristics of Pre-eclamptic (Cases) and Normotensive (Controls) Pregnant Women and their Babies.

\begin{tabular}{|c|c|c|c|c|c|c|}
\hline Variables & $\begin{array}{c}\text { Cases } \\
(\mathbf{n}=79) \\
\text { mean } \pm \text { sem } \\
\end{array}$ & $\begin{array}{l}\text { Controls } \\
(\mathbf{n}=\mathbf{8 0}) \\
\text { mean } \pm \text { sem }\end{array}$ & t-value & p-value & $\mathrm{X}^{2}$-value & p-value \\
\hline Mothers & $* 30 \pm 0.7$ & $* 29 \pm 0.5$ & .739 & 084 & & \\
\hline \multicolumn{7}{|l|}{ Age (years } \\
\hline Age distribution (15-24) years & $6(8.6 \%)$ & $9(11.3 \%)$ & & & 2.969 & 0.05 \\
\hline Age distribution $(25-34)$ years & $49(70 \%)$ & $62(77.5 \%)$ & & & & \\
\hline Age distribution $\geq$ (35years) & $15(21.4 \%)$ & $9(11.3 \%)$ & & & & \\
\hline Gestation age (at term) (weeks) & $* 35.7 \pm 0.0 .4$ & $* 38.4 \pm 0.2$ & 5.696 & 0.000 & & \\
\hline \multicolumn{7}{|l|}{ Occupation: } \\
\hline Civil servant & $35(43.8 \%)$ & $36(51.4 \%)$ & & & 17.252 & 0.101 \\
\hline Self employed & $23(32.9 \%)$ & $21(26.3 \%)$ & & & & \\
\hline Students & $17(21.3 \%)$ & $7(10 \%)$ & & & & \\
\hline Applicants & $0(0 \%)$ & $5(6.3 \%)$ & & & & \\
\hline House wife & $4(5.7 \%)$ & $2(2.5 \%)$ & & & & \\
\hline Parity & $* 0.84 \pm 0.1$ & $* 0.68 \pm 0.1$ & 0.978 & 0.33 & & \\
\hline \multicolumn{7}{|l|}{ Mode of Delivery: } \\
\hline Safe Vaginal Delivery & $13(18.6 \%)$ & $56(70 \%)$ & & & 39.752 & 0.000 \\
\hline Caesarian Section & $57(81.4 \%)$ & $24(30 \%)$ & & & & \\
\hline Progression to Eclampsia & $17(24.3 \%)$ & $0(0 \%)$ & & & 140.0 & 0.000 \\
\hline Mortality (Mother) & $2(2.9 \%)$ & $0(0 \%)$ & & & 2.317 & 0.05 \\
\hline No of life babies & $61(87.1 \%)$ & $79(98.8 \%)$ & & & 8.084 & 0.05 \\
\hline No of dead babies & $9(12.9 \%)$ & $1(1.3 \%)$ & & & & \\
\hline \multicolumn{7}{|l|}{ Babies } \\
\hline Gender: & & & & & 1.56 & 0.251 \\
\hline Male & $31(44.2 \%)$ & $43(53.8 \%)$ & & & & \\
\hline Female & $39(55.7 \%)$ & $37(46.3 \%)$ & & & & \\
\hline
\end{tabular}

Adeosun et. al., $2019^{44}$ 
Table 2: Base line and post-partum Anthropometric and Clinical Characteristics of Pre-eclamptic and Normotensive Pregnant Women (phase 1)
Variables
Pre eclamptics
Normotensives
t-value
$P$-value

Anthropometry

BMI at $3^{\text {rd }}$ trimester $\quad 29.6 \pm 6.4 \quad 28.3 \pm 5.0 \quad \mathrm{p}>0.17$

BMI at 3days postpartum $\quad 26.8 \pm 6.1 \quad 26.1 \pm 4.9 \quad \mathrm{p}>0.47$

Clinical

\section{Blood Pressure}

SBP at $3^{\text {rd }}$ trimester $166 \pm 3.0 \quad 122 \pm 1.0 \quad \mathrm{p}<0.001$

DBP at $3^{\text {rd }}$ trimester $107 \pm 2.0 \quad 78 \pm 9.0 \quad \mathrm{p}<0.001$

SBP at 3days postpartum $142 \pm 2.0 \quad 114 \pm 1.0 \quad \mathrm{p}<0.001$

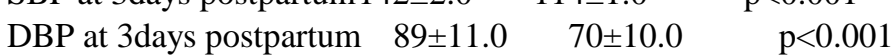

Adeosun et. al.,2019 [ 44]

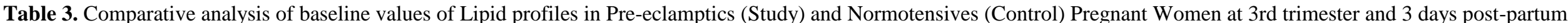

\begin{tabular}{|c|c|c|c|c|c|c|c|c|c|c|c|c|c|c|c|c|c|c|}
\hline Variables & $\begin{array}{l}\text { Triglyce } \\
\text { mes:= }=0\end{array}$ & de (mmol) & & Total & $\begin{array}{l}\text { lesterol (r) } \\
\text { mesn= }\end{array}$ & $\begin{array}{l}\mathrm{mol} / \mathrm{L}) \\
\mathrm{gem}\end{array}$ & $\begin{array}{l}\mathrm{HDL}-\mathrm{Ch} \\
\text { mes:=:s }\end{array}$ & lesterol(m & 101/L) & $\overline{L D L}-\mathrm{C}$ & lesterol & & VLDL & & & CAD R & isk Ratio & \\
\hline $\begin{array}{l}\text { Gastation } \\
\text { age }\end{array}$ & Study & $\begin{array}{l}\text { Con } \\
\text { trol }\end{array}$ & $\begin{array}{c}\text { P. } \\
\text { value }\end{array}$ & Study & Contrd & $\begin{array}{c}\text { P- } \\
\text { value }\end{array}$ & Study & Control & P -valus & Study & Control & P -valus & Study & $1^{\text {Contro }}$ & $\begin{array}{l}\text { p- } \\
\text { value }\end{array}$ & Study & Control & P-ralue \\
\hline $\begin{array}{c}3^{\text {He }} \\
\text { Trimester }\end{array}$ & $1.6=0.1$ & $1.2=0.0$ & $\mathrm{P}<0.001^{*}$ & $4.6=0.1$ & $\begin{array}{l}3 \\
.9=0.1\end{array}$ & $\begin{array}{c}P \\
<0.001^{*}\end{array}$ & $\begin{array}{l}1.8=0.0 \\
\text { protective }\end{array}$ & $1.6=0.0$ & $P<0.001^{*}$ & $2.0=0.1$ & $1.7=0.1$ & $P<0.02^{4}$ & $0.32=0.01$ & $0.24=0.0$ & $\mathrm{p}<0.05$ & 1.11 & 1.10 & $p=0.05$ \\
\hline $\begin{array}{l}\text { 3dayspost- } \\
\text { partum }\end{array}$ & $1.2=0.0$ & $1.1=0.0$ & $\begin{array}{c}P \\
=0.06\end{array}$ & $3.9=0.1$ & $3.7=0.1$ & $P>0.34$ & $2.0=0.0$ & $1.7=0.01$ & $P<0.001^{*}$ & $1.3=0.1$ & $1.6=0.8$ & $P<0.02^{4}$ & $0.24=0.01$ & $0.22=0.02$ & $\mathrm{p} \geqslant 0.05$ & $0,6 \mathrm{~s}=0.03$ & $0.94=0.01$ & $\mathrm{P}<0.001$ \\
\hline
\end{tabular}

Table 4: Baseline value of Clinical and Biochemical Parameters of Mild and Severe preeclampsia

\begin{tabular}{|l|l|l|l|}
\hline Variables & $\begin{array}{l}\text { Mild Preeclampsia } \\
(\mathrm{N}=25) \\
\text { mean } \pm \text { sen }\end{array}$ & $\begin{array}{l}\text { Severe Preeclampsia(N=45) } \\
\text { mean } \pm \text { sen }\end{array}$ & $\mathrm{p}$-value \\
\hline Age & $29 . .96 \pm 1.01$ & $30.51 \pm 0.84$ & $\mathrm{p}>0.05$ \\
\hline Gestation age & $36.84 \pm 0.61$ & $35.13 \pm 0.56$ & $\mathrm{p}>0.05$ \\
\hline Systolic blood pressure $(\mathrm{mm} / \mathrm{Hg})$ & $168.18 \pm 20.85$ & $184.44 \pm 12.92$ & $\mathrm{P}<0.005$ \\
\hline Diastolic blood pressure $(\mathrm{mm} / \mathrm{Hg})$ & $110.91 \pm 3.22$ & $120.00 \pm 8.17$ & $\mathrm{P}<0.001$ \\
\hline Body Mass Index & $29.82 \pm 1.45$ & $29.43 \pm 0.87$ & $\mathrm{p}>0.05$ \\
\hline
\end{tabular}




\begin{tabular}{|l|l|l|l|}
\hline Triglyceride $(\mathrm{mmol} / \mathrm{L})$ & $1.6 \pm 0.1$ & $1.5 \pm 0.1$ & $\mathrm{p}>0.05$ \\
\hline Total Cholesterol (mmol/L) & $4.6 \pm 0.1$ & $4.5 \pm 0.2$ & $\mathrm{p}>0.05$ \\
\hline HDL-Cholesterol (mmol/l) & $1.8 \pm 0.1$ & $1.7 \pm 0.5$ & $\mathrm{p}>0.05$ \\
\hline LDL-Cholesterol (mmol/L) & $2.0 \pm 0.2$ & $2.1 \pm 0.2$ & $\mathrm{p}>0.05$ \\
\hline VLDL-C & $0.32 \pm 0.01$ & $0.31 \pm 0.01$ & $\mathrm{p}>0.05$ \\
\hline CAD-Risk- Ratio (TC/HDL) & $2.5 \pm 0.1$ & $2.7 \pm 0.2$ & $\mathrm{p}>0.05$ \\
\hline
\end{tabular}

Phase 2

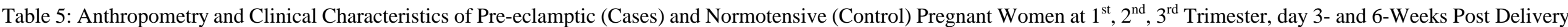

\begin{tabular}{|c|c|c|c|c|c|c|c|c|c|c|c|c|}
\hline Variable & \multicolumn{3}{|c|}{ Body Mass Index } & \multicolumn{3}{|c|}{ Systolic blood pressure (mm/hg) } & \multicolumn{3}{|l|}{$\begin{array}{l}\text { Diastolic } \\
(\mathrm{mm} / \mathrm{hg})\end{array}$} & \multicolumn{3}{|c|}{ Micro albuminuria $(\mathrm{g} / \mathrm{L})$} \\
\hline Gest.Age & $\begin{array}{l}\text { Cases } \\
{[10]} \\
\text { mean } \pm \text { se } \\
\text { m }\end{array}$ & $\begin{array}{l}\text { Control } \\
{[20]} \\
\text { manse }\end{array}$ & $\begin{array}{l}\text { P-va } \\
\text { lue }\end{array}$ & $\begin{array}{l}\text { Cases } \\
{[10]} \\
\text { mean } \pm \text { se } \\
\text { m }\end{array}$ & $\begin{array}{l}\text { Control } \\
\text { [20] } \\
\text { manse }\end{array}$ & $e^{p-v a l u}$ & $\begin{array}{l}\text { Cases } \\
{[10]} \\
\text { mean } \pm s \\
\text { em }\end{array}$ & $\begin{array}{l}\text { Control } \\
{[20]} \\
\text { mean } \pm \text { se } \\
\text { m }\end{array}$ & lue $^{p-v a}$ & $\begin{array}{l}\text { Cases [10] } \\
\text { mean } \pm \text { sem }\end{array}$ & $\begin{array}{l}\text { Control } \\
{[20]} \\
\text { mean } \pm \text { se } \\
\text { m }\end{array}$ & p-value \\
\hline $\begin{array}{c}1^{\text {st }} \\
\text { trimester }\end{array}$ & $28.7 \pm 2.4$ & $3^{27.1 \pm 1 .}$ & $05^{p>0 .}$ & $116.0 \pm 3.4$ & $.2^{111.5 \pm 2}$ & $\mathrm{p}>0.05$ & $5^{69.0 \pm 3 .}$ & $67.5 \pm 2.2$ & ${ }_{05^{p}}^{p>0 .}$ & $2.7 \pm 0.5$ & $3.9 \pm 0.6$ & $\mathrm{p}>0.05$ \\
\hline 2nd trimester & $30.6 \pm 2.7$ & $4^{29.3 \pm 1 .}$ & $05^{p>0 .}$ & $145.0 \pm 6.2$ & $.8^{111.0 \pm 3}$ & $\begin{array}{l}\quad \mathrm{P}<0.0 \\
0^{*}\end{array}$ & $0^{93.0 \pm 6 .}$ & $65.0 \pm 2.0$ & $\begin{aligned} \mathrm{P}<0 . \\
05^{*}\end{aligned}$ & $96.0 \pm 15.6$ & $8.6 \pm 0.7$ & $\mathrm{P}<005 *$ \\
\hline 3rd trimester & $31.8 \pm 2.7$ & $3^{30.5 \pm 1 .}$ & $05^{p>0 .}$ & $149.0 \pm 3.8$ & $\begin{array}{l}109.0 \\
\pm 3.7 \\
\end{array}$ & $\begin{array}{l}\quad \mathrm{P}<0.0 \\
0 *\end{array}$ & $3^{98.0 \pm 3 .}$ & $65.0 \pm 2.0$ & $\begin{array}{c}\mathrm{P}<0 . \\
000^{*}\end{array}$ & $263.5 \pm 23.1$ & $31.4 \pm 6.4$ & $\begin{array}{l}\mathrm{P}<0.00 \\
5^{*}\end{array}$ \\
\hline 3days post & $29.8 \pm 2.8$ & $3^{28.4 \pm 1 .}$ & $05^{p>0 .}$ & $\begin{array}{ll}130.0 & \pm \\
3.7^{1} & \end{array}$ & $\begin{aligned} & 115.0 \\
& \pm 2.0 \\
&\end{aligned}$ & $\begin{array}{l}\quad \mathrm{P}<0.0 \\
0 *\end{array}$ & $8^{89.0 \pm 3 .}$ & $69.5 \pm 2.2$ & $\begin{array}{l}\mathrm{P}<0 . \\
000^{*}\end{array}$ & $103 \pm 14.3$ & $11.3 \pm 2.5$ & $\mathrm{P}<000^{*}$ \\
\hline 6days post & $29 . \pm 2.8$ & $3^{28.3 \pm 1 .}$ & $05^{p>0 .}$ & $100.0 \pm 3.7$ & $2.3^{119.0 \pm}$ & $\begin{array}{l}\mathrm{P}<0.0 \\
5^{*}\end{array}$ & $8^{63.0 \pm 2 .}$ & $74.0 \pm 1.9$ & $\begin{array}{r}\mathrm{P}<0 . \\
002 *\end{array}$ & $7.4 \pm 1.5$ & $1.4 \pm 0.2$ & $\mathrm{P}<000^{*}$ \\
\hline
\end{tabular}

(Adeosun et al., 2019) [44]

Table 6: Serum levels of the Plasma Lipids in Preeclamptics (Cases) and Normotensive (Controls) pregnancy from $1^{\text {st }}$ Trimester to 6 weeks post-partum.

\begin{tabular}{|c|c|c|c|c|c|c|c|c|c|c|c|c|c|c|c|c|c|c|}
\hline Variable & Tri & $\begin{array}{l}\text { yceride ( } \\
\text { mean } \pm s\end{array}$ & $\mathrm{~mol} / \mathrm{L})$ & Total & $\begin{array}{l}\text { olesterol } \\
\text { nean } \pm \text { ser }\end{array}$ & $\mathrm{nmol} / \mathrm{L})$ & HDL & $\begin{array}{l}\text { holesterol } \\
\text { mean } \pm \text { ser }\end{array}$ & $\mathrm{Amol} / \mathrm{L})$ & $\begin{array}{l}\text { LDL-C } \\
\text { mean } \pm s\end{array}$ & $\begin{array}{l}\text { lesterol } \\
\text { n }\end{array}$ & & $\begin{array}{l}\text { VLDL-Ch } \\
\text { mean } \pm \text { sen }\end{array}$ & lesterol; & & $\begin{array}{l}\text { CAD Ris } \\
\text { TC/HDI }\end{array}$ & Ratio & \\
\hline Gest.Age & $\begin{array}{l}\text { Cases } \\
10\end{array}$ & $\begin{array}{l}\text { Control } \\
20\end{array}$ & p-value & $\begin{array}{l}\text { Cases } \\
10\end{array}$ & $\begin{array}{l}\text { Control } \\
20\end{array}$ & p-value & $\begin{array}{l}\text { Cases } \\
10\end{array}$ & $\begin{array}{l}\text { Control } \\
20\end{array}$ & p-value & $\begin{array}{l}\text { Cases } \\
10\end{array}$ & $\begin{array}{l}\text { Control } \\
20\end{array}$ & p-value & $\begin{array}{l}\text { Cases } \\
10\end{array}$ & $\begin{array}{l}\text { Control } \\
20\end{array}$ & p-value & Case & Control & $\mathrm{p}$-value \\
\hline $\begin{array}{l}1^{\mathrm{st}} \\
\text { trimester }\end{array}$ & $1.3 \pm 0.1$ & $1.0 \pm 0.0$ & $\mathrm{P}<0.023^{*}$ & $3.7 \pm 0.3$ & $3.3 \pm 0.2$ & $\mathrm{P}<0.03$ & $1.6 \pm 0.0$ & $1.7 \pm 0.0$ & $\begin{array}{l}\mathrm{P}<0.009^{*} \\
\end{array}$ & $1.5 \pm 0.3$ & $1.0 \pm 0.1$ & $P<0.012$ & $0.26 \pm 0.01$ & $\mathrm{O}, 20 \pm 0.02$ & $\mathrm{P}<0.05$ & $2.3 \pm 0.01$ & $1.9 \pm 0.00$ & $\mathrm{P}<0.0 .001$ \\
\hline 2nd trimester & $1.7 \pm 0.1$ & $1.1 \pm 0.0$ & $\mathrm{P}<0.000^{*}$ & $4.2 \pm 0.3$ & $3.5 \pm 0.1$ & $\mathrm{P}<0.020^{*}$ & $1.6 \pm 0.0$ & $1.60 \pm 1.3$ & $P>0.46$ & $1.8 \pm 0.3$ & $1.4 \pm 0.3$ & $\mathrm{P}<0.177$ & $0.34 \pm 0.02$ & $0.22 \pm 0.00$ & $\mathrm{P}<0.003$ & $2.6 \pm 0.01$ & $1.9 \pm 0.02$ & $\mathrm{P}<0.05$ \\
\hline
\end{tabular}


ISSN: 2454-8236, Volume-10, Issue-4, April 2021 Pages 12-25

\begin{tabular}{|c|c|c|c|c|c|c|c|c|c|c|c|c|c|c|c|c|c|c|}
\hline 3rd trimester & $1.9 \pm 0.1$ & $1.2 \pm 0.0$ & $\mathrm{P}<0.000$ & $4.7 \pm 0.3$ & $4.1 \pm 0.1$ & $\mathrm{P}<0.026$ & $2.0 \pm 0.0$ & $1.5 \pm 0.0$ & $\mathrm{P}<* 0.000$ & $1.9 \pm 0.2$ & $2.0 \pm 0.0$ & $P>0.568$ & $0.38 \pm 0.01$ & $0.24 \pm 0.0$ & $P<0.05$ & $2.4 \pm 0.01$ & $2.7 \pm 0.00$ & $\mathrm{P}<0.01$ \\
\hline 3days post & $1.7 \pm 0.1$ & $1.2 \pm 0.0$ & $\mathrm{p}<* 0.001$ & $4.1 \pm 0.0 .2$ & $3.8 \pm 0.2$ & $\mathbf{P}<\mathbf{0 . 0 2}$ & $1.7 \pm 0.0$ & $1.6 \pm 0.0$ & $\mathrm{P}<0.046$ & $1.7 \pm 0.2$ & $1.7 \pm 0.2$ & $\mathrm{p}>0.947$ & $0.34 \pm 0.00$ & $0.24 \pm 0.00$ & $\mathrm{P}<0.05$ & $2.3 \pm 0.01$ & $2.2 \pm 0.02$ & $p>0.05$ \\
\hline 6days post & $1.2 \pm 0.1$ & $1.0 \pm 0.0$ & $\mathrm{P}<0.035^{*}$ & $3.7 \pm 0.2$ & $3.1 \pm 0.1$ & $\mathrm{P}<0.010^{*}$ & $1.8 \pm 0.14$ & $1.5 \pm 0.0$ & $\mathrm{P}<0.000^{*}$ & $1.3 \pm 0.2$ & $1.2 \pm 0.1$ & $\mathrm{p}>0.594$ & $0.24 \pm 0.03$ & $0.20 \pm 0.02$ & $p>0.05$ & $2.1 \pm 0.00$ & $1.9 \pm 0.02$ & $p>0.05$ \\
\hline
\end{tabular}

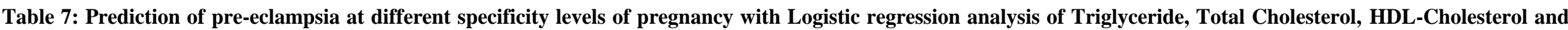
LDL-Cholesterolat1st, $2^{\text {nd, }}$ and $3^{\text {rd }}$ trimester in Pregnancy complicated with Pre-eclampsia.

Gestation age

Variables

Odds Ratio

\section{Confidence} Interval

$\mathbf{1}^{\text {st }}$ trimester $\left(10.9^{\text {th }}\right.$ week $)$

$2^{\text {nd }}$ trimester $\left(23 .^{\text {nd }}\right.$ week $)$

$3^{3 \mathrm{rd}}$ trimester $\left(34.5^{\text {th }}\right.$ week $)$
Triglyceride

Total-cholesterol

HDL-Cholestero

LDL-Cholestero

Triglyceride

Total-cholesterol

HDL-Cholesterol

LDL-Cholesterol

Triglyceride

Total-cholesterol

HDL-Cholesterol

LDL-Cholesterol
1.046-857.998

0.000-3.8956

$0.000-122.127$

0.000-2.7458

7.169-9.5138

0.000-5.512

0.000-3.122

6.851-2.325

6.851-2.3525

0.000-5.494

0.000-5.481

0.0000-5.186
P-value

$0.047^{*}$

0.843

0.094

0.764

0.018 *

0.522

0.385

0.530

0.011 *

0.327

0.169

0.312 


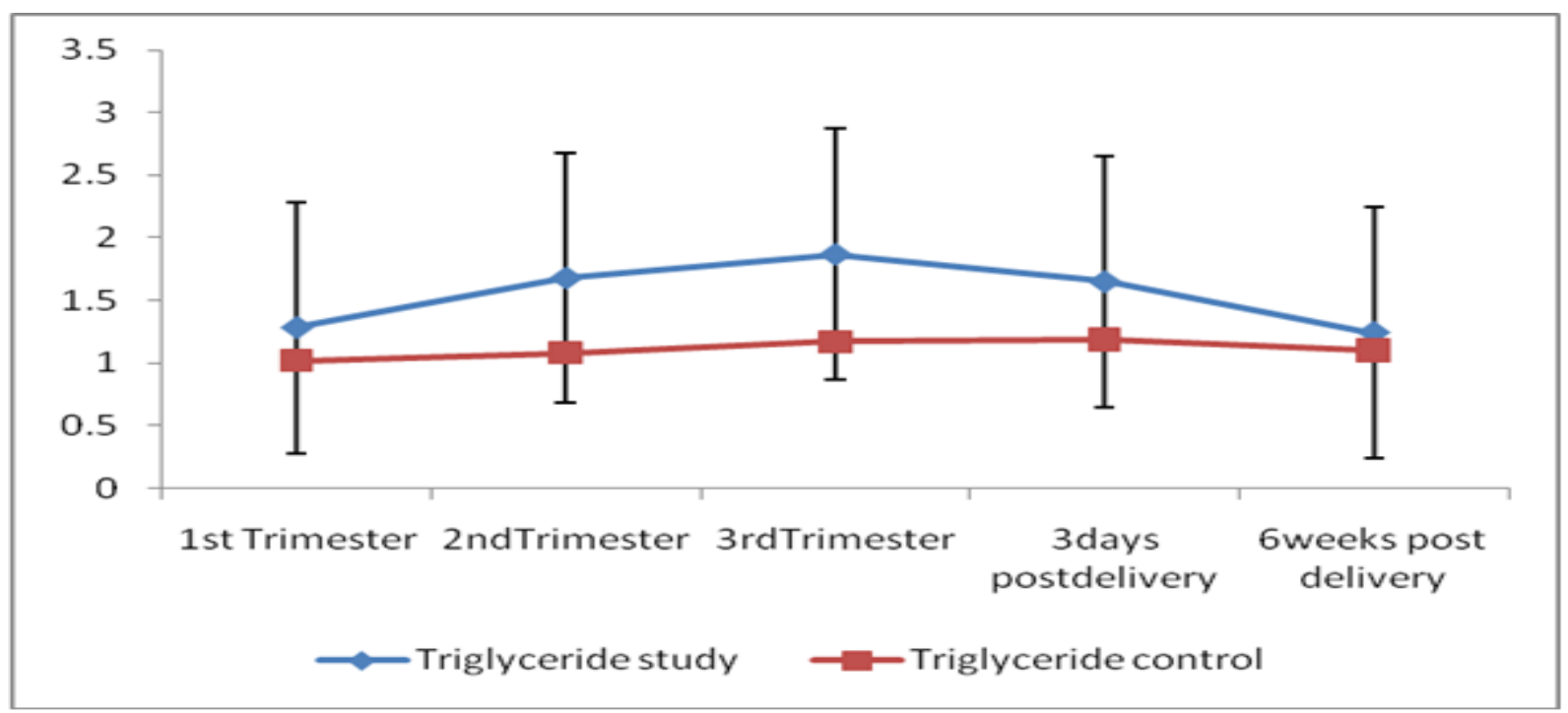

Figure 1: Line graph showing the pattern of alteration of plasma Triglyceride in both control and study subjects from 1st trimester to 6 weeks post-partum.

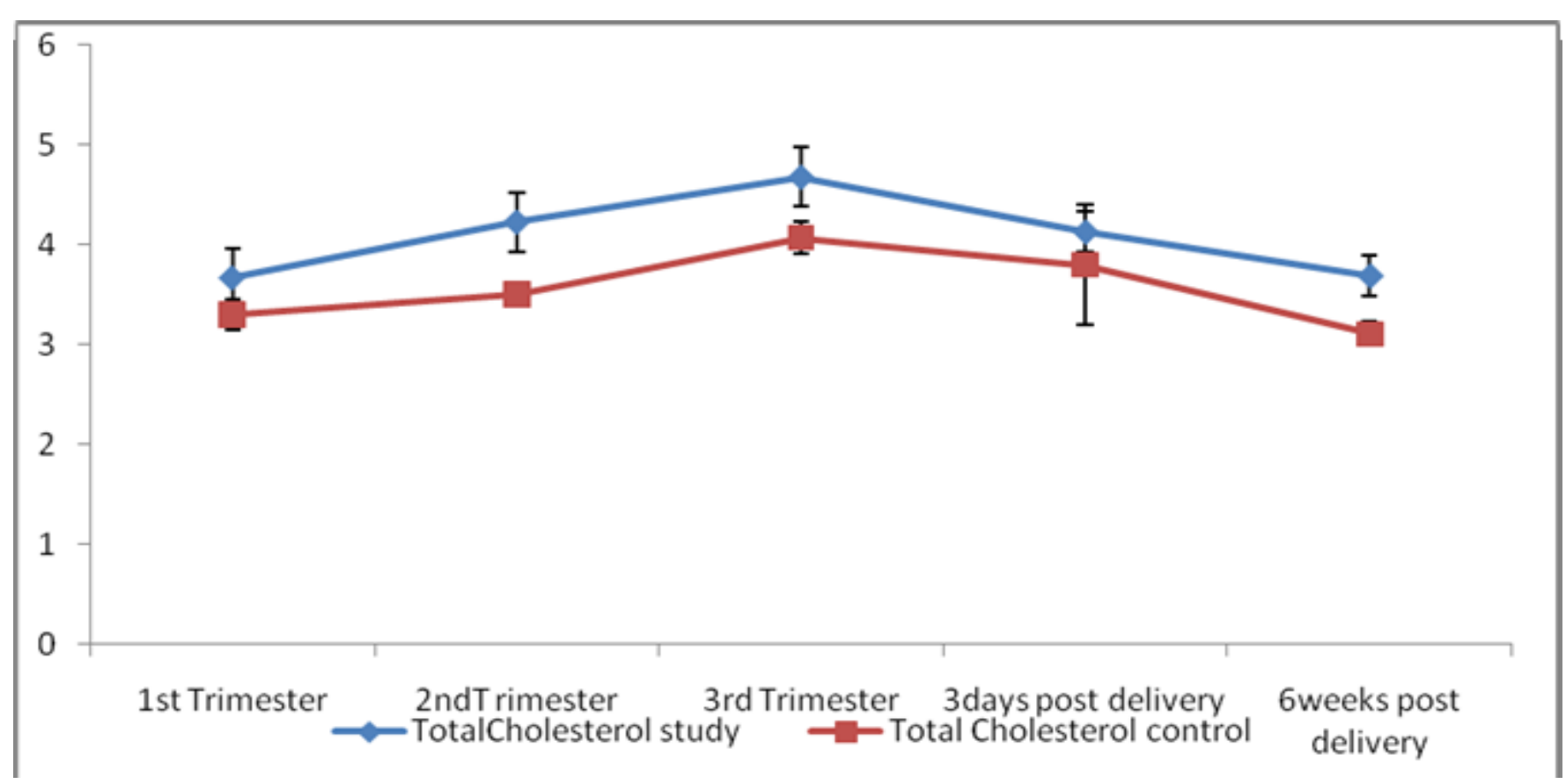


Figure 2: Line graph showing the pattern of alteration of plasma Total Cholesterol in both control and study subjects from 1st trimester to 6 weeks post-partum.

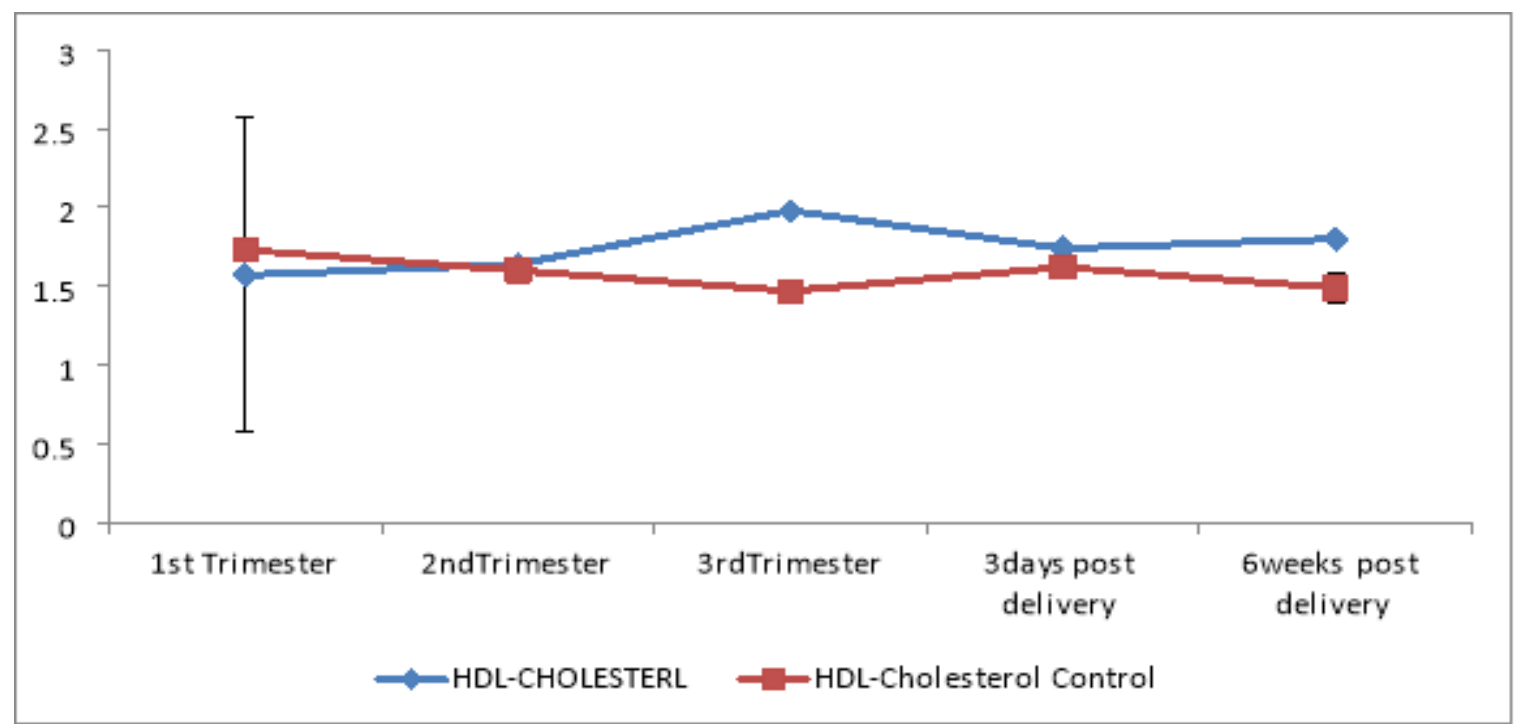

Figure 3: Line graph showing the pattern of alteration of plasma HDL-Cholesterol in both control and study subjects from 1st trimester to 6 weeks post-partum.

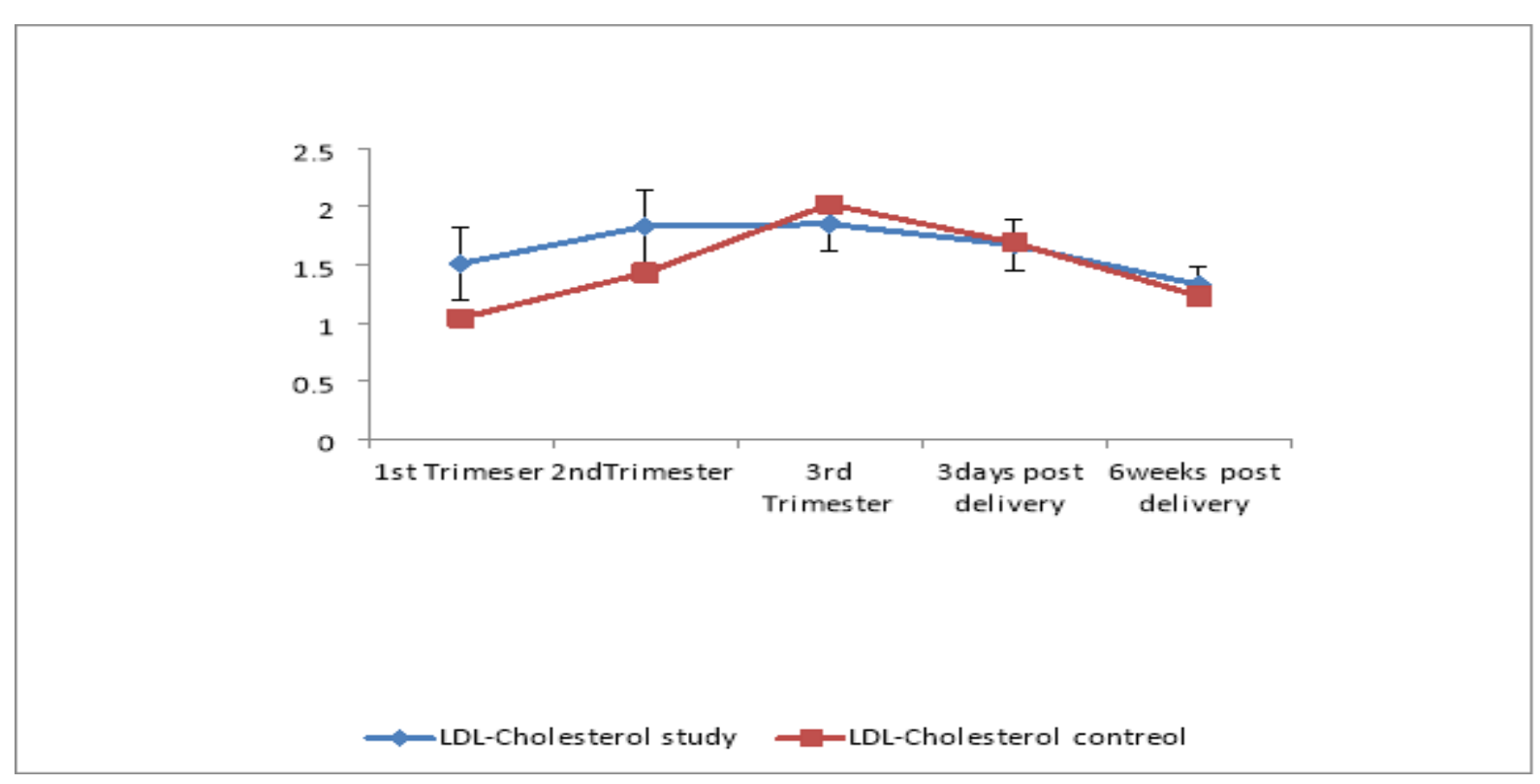


Figure 4: Line graph showing the pattern of Plasma LDL-Cholesterol in both control and study subjects from 1st trimester to 6 weeks post-partum.

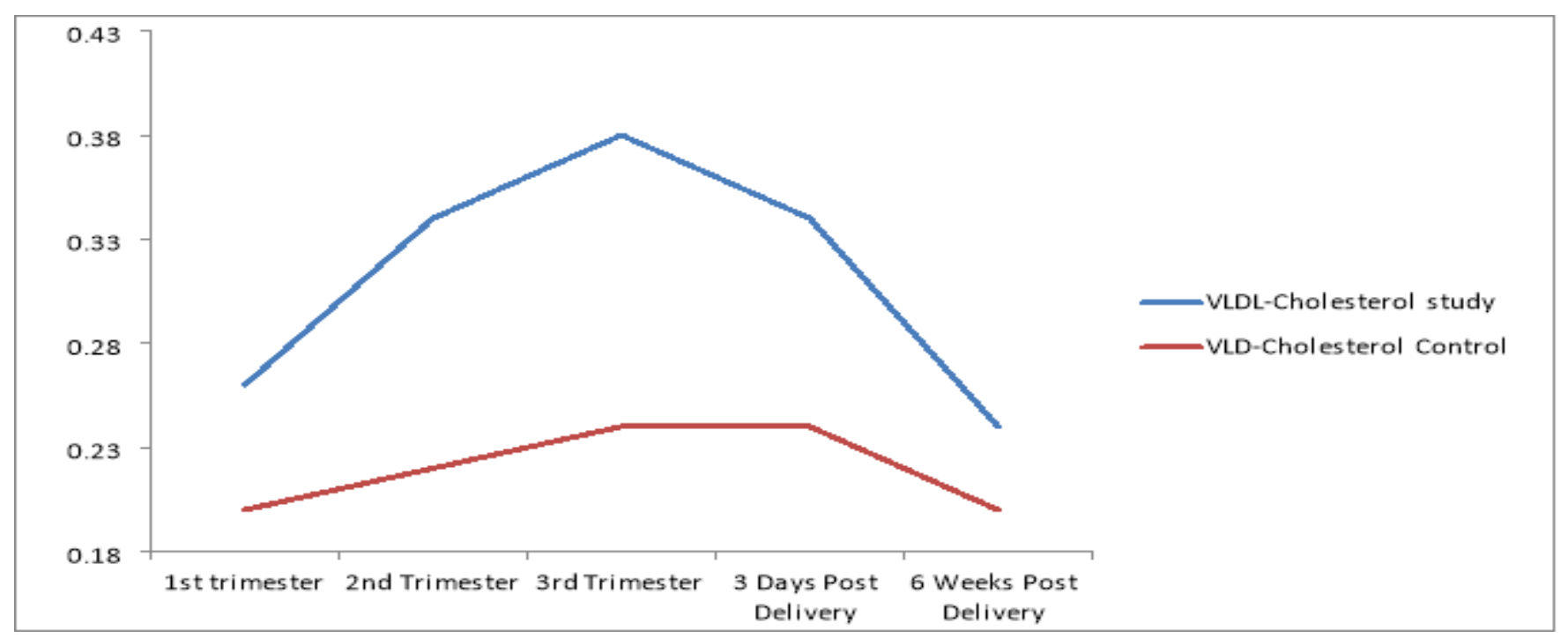

Figure 5: Line graph showing the pattern of Plasma V LDL-Cholesterol in both control and study subjects from 1st trimester to 6 weeks post-partum.

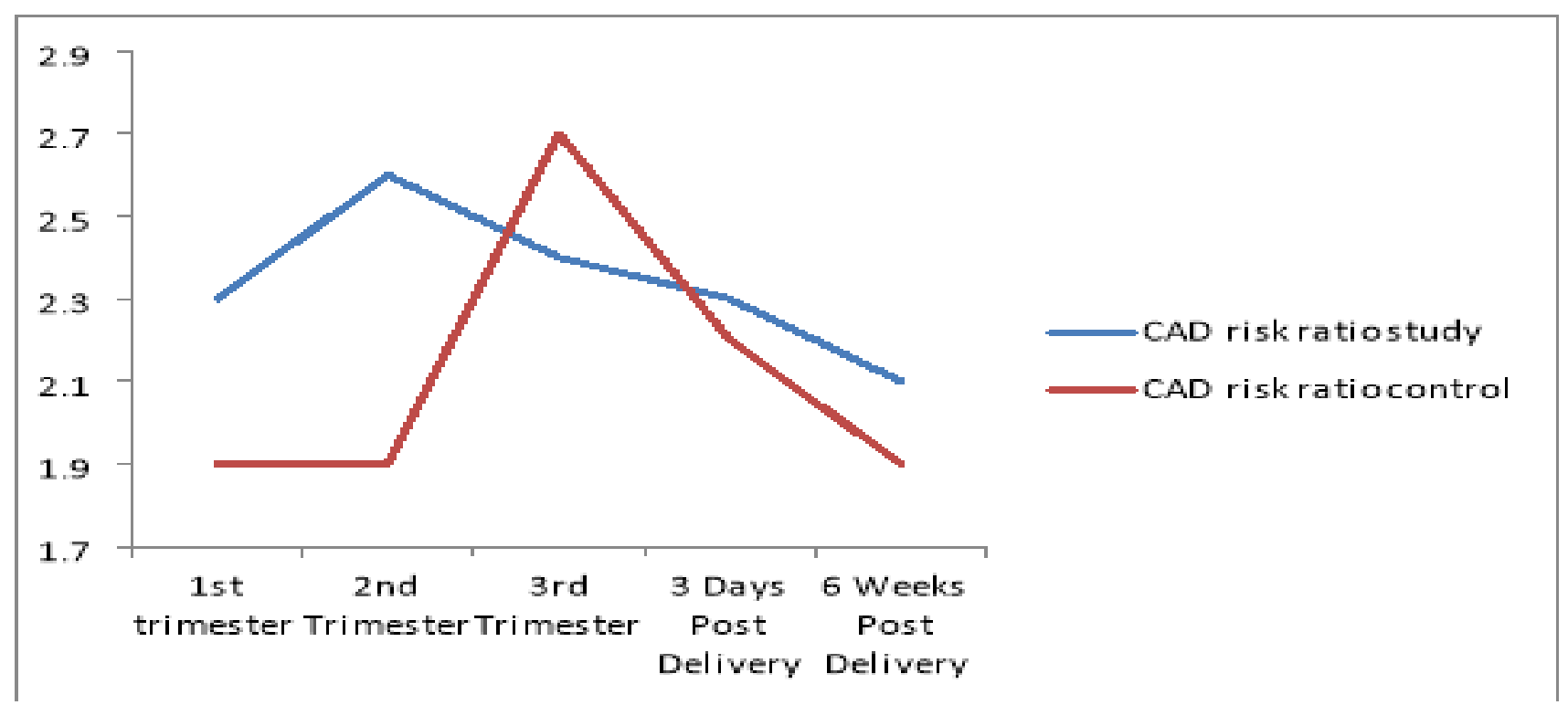

Figure 6: Line graph showing the pattern of CAD Risk Ratio in both control and study subjects from 1st trimester to 6 weeks post-partum 


\section{Acknowledgment}

The authors sincerely appreciate the Departments of Obstetrics and Gynaecology of the Obafemi Awolowo University Teaching Hospital (OAUTHC) Ile-Ife and its Ethical and Research Committee for allowing us access to their antenatal patients selected for this study. Without them, the study may not achieve its target. We equally acknowledge the professional staff in the laboratory. The gravid women that constituted the cases and reference subjects, we appreciate and thank them for their participation and wonderful cooperation.

\section{Financial disclosures}

This research was self-financed; authors have no access to any grant or funding agency.

\section{Disclosure}

The authors declare that they have no conflicts of interest in this work.

\section{REFERENCES}

[1] Habimana-Kabano, I., Broekhuis, A., \& Hooimeijer, P. (2015). Inter-Pregnancy Intervals and Maternal Morbidity: New Evidence from Rwanda. African Journal of Reproductive Health / La Revue Africaine De La Santé Reproductive, 19(3), 77-86. Retrieved May 9, 2020, from www.jstor.org/stable/24877834

[2] ACOG Practice Bulletin No. 202: Gestational Hypertension and Preeclampsia. Obstet Gynecol [Internet]. 2019 [cited 2018 Dec 26]; 133: e1-25. Available from: http://www.ncbi.nlm.nih.gov/ PubMed/30575675.

[3] L.A. Magee, A. Pels, M. Helewa, et al., The hypertensive disorders of pregnancy (29.3), Best Practice Res. Clin. Obstet. Gynaecol. 29 (5) (2015) 643-657.

[4] Stuart, Jennifer J., et al. "Abstract MP63: Established Cardiovascular Disease Risk Factors Mediate the Relationship Between Hypertensive Disorders in First Pregnancy and Maternal Cardiovascular Disease." Circulation, vol. 141, 2020.

[5] Akeju DO, Vidler M, Oladapo OT, Sawchuck D, Qureshi R, von Dadelszen $\mathrm{P}$, et al. Community perceptions of pre-eclampsia and eclampsia in Ogun State, Nigeria: a qualitative study. Reprod Health. 2016; 13: 57. PubMed: www.ncbi.nlm.nih.gov/pubmed/27357695

[6] Oloruntoba Ayodele Ekun, Oluwatumininu Mary Olawumi, Christian Chigozie Makwe, Nkeiruka Ogochukwu Ogidi. Biochemical assessment of renal and liver function among preeclamptics in Lagos metropolis. International Journal of Reproductive medicine. 2018. http://bit.ly/2M59J7d

[7] P.von Dadelszen, L.A. Magee, Preventing deaths due to the hypertensive disorders of pregnancy, Best Practice Res. Clin. Obstet. Gynaecol. 36 (2016) 83-102. [5]

[8] Khanum S, Naz N, Souza M. Prevention of pre-eclampsia and eclampsia. A systematic review. Open Journal of Nursing. 2018; 8 : 26-44. http://bit. ly/2rXSsWC

[9] Santo Monte. Biochemical markers for prediction of pre-eclampsia: a review of the literature. J Prenatal Med. 2011; 5: 69-77. http://bit.ly/2YZSR6P

[10] Gilles Guerrier, Bukola Oluyide, Maria Keramarou, Rebecca F Grais. Factors associated with severe preeclampsia and eclampsia in Jahun, Nigeria. Int J Women's Health. 2013; 5: 509-513. PubMed: https://www.ncbi.nlm.nih.gov/ pubmed/23983493/

[11] Okusanya BO, Aigere EO, Abe A, Ibrahim HM, Salawu RA. Maternal deaths: initial report of an ongoing monitoring of maternal deaths at the Federal Medical Centre Katsina, Northwest Nigeria. J Matern Fetal Neonatal Med. 2013; 26(9):885-888.

[12] Arvizu, M., Affiche, M.C., Hansen, S. et al. Fat intake during pregnancy and risk of preeclampsia: a prospective cohort study in
Denmark. Eur J Clin Nutr 73, 1040-1048

(2019) https://doi.org/10.1038/s41430-018-0290-Z

[13] McKinley M.C., Francis J.J., Woodside J.V. (2017) Pregnancy: Preparation for the Next Generation. In: Temple N., Wilson T., Bray G. (eds) Nutrition Guide for Physicians and Related Healthcare Professionals. Nutrition and Health. Humana Press, Cham

[14] Al-Nasiry, S., Ghossein-Doha, C., Polman, S., Lemmens, S., Scholten, R., Heidema, W., Spaanderman, M. Metabolic syndrome after pregnancies complicated by pre-eclampsia or smallfor-gestational-age: a retrospective cohort. BJOG: An International Journal of Obstetrics \& Gynaecology, 2014: 122(13), 1818-1823. doi:10.1111/1471-0528.13117

[15] Adeosun OG, Charles Davies MA, Ogundahunsi, OA Ogunlewe J. Preliminary evaluation of hormonal and metabolic dysfunction: potential indicators of pre-eclampsia in African black women, southwest Nigeria. Sky Journal of Medicine and Medical Sciences. 2016; 4: 7-13.

[16] Umoh U, Charles-Davies MA, Adeleye A Serum testosterone and lipids in relation to sexual dysfunction in males with metabolic syndrome and type 2 diabetes mellitus, Int. J. Med. Sci., 2010: 2: 402-412.

[17] Cole TG, Klotzsch SG, McNamara Measurement of triglyceride concentration. In: Rifai N, Warnick GR, Dominiczak MH, eds Handbook of lipoprotein testing. Washington: AACC Press, 1997: pp.115-26.

[18] Trinder P Determination of glucose in blood using glucose oxidase with an alternative oxygen acceptor. Ann. Clin. Biochem., 1969: 6 24-27.

[19] N.C.E.P. Second report of the expert panel on detection, evaluation, and treatment of high blood cholesterol in adults. Circulation1994; 89:1329-34

[20] Frieldwald WT, Levy RI, Fredricson DS. Estimation of the concentration of low- density lipoprotein cholesterol in plasma without the use of a pre-preparation ultracentrifuge. Clin. Chem., 1972:18: 499-502.

[21] National High Blood Pressure Education Program. Report of the National High Blood Pressure Education Program Working Group on high blood pressure in pregnancy. Am J Obstet Gynecol. 2000; 183: 119-122. PubMed: https://www.ncbi.nlm.nih.gov/pubmed/10920346

[22] Rendon Macias ME, Villasis Keever MA. The research protocol V: The calculation of sample size. Rev Alerg Mex. 2017; 64: 220-227. PubMed: https://www.ncbi.nlm.nih.gov/pubmed/28658730

[23] Okala SG, Sise EA, Sosseh F, Prentice AM, Woollett LA, Moore SE. Maternal plasma lipid levels across pregnancy and the risks of small-for-gestational age and low birth weight: a cohort study from the rural Gambia. BMC Pregnancy Childbirth. 2020 Mar 12; 20(1):153. doi: $10.1186 / \mathrm{s} 12884-020-2834-1$

[24] Neboh EE, Emeh JK, Aniebue UU, Ikekpeazu EJ, Maduka IC, Ezeugwu FO. Relationship between lipid and lipoprotein metabolism in trimesters of pregnancy in Nigerian women: Is pregnancy a risk factor? J Nat Sc Biol Med 2012; 3:32-7.

[25] Singh A, Kujur A, Jain P. Feto-maternal impact of altered lipid profile in pregnancy. Int J Reprod Contracept Obstet Gynecol 2018; 7:132-6.

[26] Ephraim R, Doe P, Amoah S, Antoh E. Lipid Profile and High Maternal Body Mass Index Is Associated with Preeclampsia: A Case-Control Study of the Cape Coast Metropolis. Ann Med Health Sci Res. 2014 Sep;4(5):746-50. doi: 10.4103/2141-9248.141542.

[27] Olalere FDH, Okusanya BO, Oye-Adeniran BA. Maternal serum lipid in women with preeclampsia in Lagos: a case-control study. J Matern Fetal Neonatal Med. 2020 Mar; 33(5):794-798. DOI: 10.1080/14767058.2018.1505851. Epub 2018 Sep 3.

[28] Timalsina S, Gyawali P, Bhattarai A. Comparison of lipid profile parameters and oxidized low-density lipoprotein between normal and preeclamptic pregnancies in a tertiary care hospital in Nepal. Int J Women's Health. 2016 Oct 26; 8:627-631. doi: 10.2147/IJWH.S117850. eCollection 2016.

[29] Aboyeji, P.A., \& Adebisi, S.A. Plasma lipids, and lipoprotein during the first trimester in pregnant Nigerian women. Ilorin Experience. Nigeria Postgraduate Medical Journal. 2004; 11(1): 1-3

[30] Ray, J.G., Diamond, P., Singh, G., \& Bell, C.M., Brief overview of maternal triglyceride as a risk factor for preeclampsia. British Journal of Obstetrics \& Gynaecology. 2006; 11; (4): 379- 86

[31] Baker AM, Klein RL, Moss KL, et al. Maternal serum dyslipidemia occurs early in pregnancy in women with mild but not severe preeclampsia. Am J Obstet. Gynecol 2009; 201:293.

[32] Bhat, P. V., Vinod, V., Naga Priyanka, A., \& Kamath, A. Maternal serum lipid levels, oxidative stress, and antioxidant activity in pre-eclampsia patients from Southwest India. Pregnancy Hypertension. 
2019 Jan; 15:130-133. doi: 0.1016/j.preghy.2018.12.010. Epub 2018 Dec 31.

[33] Adank MC, Benschop L, Peterbroers KR, et al. Is maternal lipid profile in early pregnancy associated with pregnancy complications and blood pressure in pregnancy and long-term postpartum? Am J Obstet Gynecol 2019; 221:150. e1-13

[34] Grimes SB, Wild R. Effect of Pregnancy on Lipid Metabolism and Lipoprotein Levels. [Updated 2018 Feb 20]. In: Feingold KR, Anawalt B, Boyce A, et al., editors. Endotext [Internet]. South Dartmouth (MA): MDText.com, Inc.; 2000-Available from: https://www.ncbi.nlm.nih.gov/books/NBK498654/

[35] Shen H, Liu X, Chen Y, et al. Associations of lipid levels during gestation with hypertensive disorders of pregnancy and gestational diabetes mellitus: a prospective longitudinal cohort study. BMJ Open 2016; 6: e013509. DOI: 10.1136/bmjopen-2016- 013509.

[36] Emilio Herrera \& Henar Ortega-Senovilla. Maternal lipid metabolism during normal pregnancy and its implications to fetal development. Pregnancy and its implications to fetal development, Clinical Lipidology, 2010- 5:6, 899-911

[37] Santos, Ana Paula Caires dos and COUTO, Ricardo David. Lipoprotein Profile Modifications during Gestation: A Current Approach to Cardiovascular risk surrogate markers and Maternal-fetal Unit Complications. Rev. Bras. Ginecol. Obstet. [online]. 2018, vol.40, n.5 [cited 2020-05-15], pp.281-286

[38] Lopes Van Balen1 V. A, Van Gansewinkel1, T. A. G., De haas1 S. et.ai.,. Physiological adaptation of endothelial function to pregnancy: systematic review and meta-analysis Ultrasound Obstet Gynecol 2017; 50: 697-708

[39] Mannaerts, D., Faes, E., Gielis, J. et al. Oxidative stress and endothelial function in normal pregnancy versus pre-eclampsia, a combined longitudinal and case- control study. BMC Pregnancy Childbirth 18, 60 (2018). https://doi.org/10.1186/s12884-018-1685-5

[40] Cortes-Vasquez, Jonathan; NORENA, Islendy, and MOCKUS, Ismena. Hypertriglyceridemia and adverse outcomes during pregnancy. rev.fac.med. [online]. 2018, vol.66, n.2 [cited 2020-05-15], pp.247-253.

[41] Anissa Ben Amor et al, Severe gestational hypertriglyceridemia: a rare but serious situation. Pan African Medical Journal. 2019; 34:13. doi:10.11604/pamj.2019.34.13.20065

[42] Alahakoon Thushari I., Medbury Heather J., Williams Helen, Lee1Vincent W. Lipid profiling in maternal and fetal circulations in preeclampsia and fetal growth restriction-a prospective case- control observational study. BMC Pregnancy and Childbirth (2020) 20:61

[43] Nidhi D, Kaur B, Fayyaz S. Study of serum lipid profile in pregnancy and its correlation with preeclampsia. Obstet Gynecol Int J. 2019; 10(3):169-174. DOI: 10.15406/ogij.2019.10.00439

[44] Adeosun GO, Charles Davies MA, Ogundahunsi OA, Ogunlewe J, Bello IS, et. al., Alteration of Serum Reproductive Hormones and the Risk of Preeclampsia in Pregnancy: A Longitudinal Study in Gravid African Women. Int J Reprod Med Gynecol. 2019; 5(2): 059-066.

[45] De J, Mukhopadhyay A, Saha P. Study of serum lipid profile in pregnancy-induced hypertension. Indian J Clin Biochem 2006; 21:165 8.

[46] Singh M, Pathak MS, Paul A. A Study on Atherogenic Indices of Pregnancy Induced Hypertension Patients as Compared to Normal Pregnant Women. J Clin Diagn Res. 2015; 9(7): BC05-BC8. doi:10.7860/JCDR/2015/13505.6241 